\title{
UM CORPUS FICCIONAL PAMPIANO: O FRONTEIRIÇO SERGIO FARACO
}

\author{
Fabiane de Oliveira Resende ${ }^{6}$
}

RESUMO: o trabalho aqui apresentado visa a uma mirada nos textos de ambientação regional do contista Sergio Faraco, na busca por elementos que constituam a especificidade de uma literatura de fronteira. Num percurso de revisão do espaço pampiano, fronteiriço, marcas da fronteira enquanto zona de contato e porosidade são trabalhadas na contística do autor sul-rio-grandense. Dentre elas, a revisitação do espaço regional, em termos de uso da linguagem, da dicotomia rural x urbano, do telurismo, da violência, do contrabando, do silêncio e da solidão de homens e mulheres relegados a um espaço sem lei e da falta de condições para a sobrevivência no outrora abastado pampa, mitificado. A leitura proposta está pautada na noção de fronteira aberta e nas múltiplas possibilidades de significado que a mesma encaminha.

Palavras-chave: Sergio Faraco. Literatura de fronteira. Espaço pampiano.

ABSTRACT: the present work aims to have a look in the regional setting texts of the short-story writer Sergio Faraco, in the search for elements constituting the specificity of a border literature. In a revision way of a pampiano space, of the border, marks of border while contact zone and porosity are worked in the short-story way of the sul-rio-grandense author. Among them, the revisiting of the regional space, as language usage, of the rural $x$ urban dichotomy, of the tellurism, of the violence, of the contraband, of the silence and of the loneliness of men and woman left in a lawless space and of the lack of conditions to survive in a once rich pampa, mythologized. The proposed reading is based in the notion of open border and in the multiple possibilities of meaning that the same forwards.

Keywords: Sergio Faraco. Border literature. Pampiano space.

${ }^{6}$ Professora substituta no Centro de Letras e Comunicação da Universidade Federal de Pelotas. Doutora em Literatura Comparada pela Universidade Federal do Rio Grande do Sul. Mestre em História da Literatura pela Universidade Federal do Rio Grande. 
Ao longo do século XX, a crítica sul-americana ocupou-se largamente com a gauchesca, uma das variações do regionalismo latinoamericano, em geral conferindo pouco valor estético aos primeiros textos, pois, segundo ela, eram excessivamente comprometidos com a tarefa de marcar a cor local e os limites geopolíticos de determinada região. Pensando no cenário literário sul-rio-grandense, especialmente a partir da produção de Cyro Martins, esse trato com o regional modifica-se na medida da renovação na ótica de percepção do gaúcho e do seu espaço, o pampa, então já não mais vistos sob a aura do mito, mas sob a desestabilização do mesmo.

Gilda Neves da Silva, em O conto sul-rio-grandense: tradição e modernidade, coloca que

[...] a marca de identidade do conto gaúcho até meados do século 20 foi o regionalismo. A partir daí, no entanto, essa feição unitária se transforma, com a introdução paulatina da narrativa urbana, que acaba sendo a característica dominante do conto na década de 1970 (SILVA, 1999, p. 122-123).

Com a desmistificação do gaúcho-mito e do seu território e a crescente tomada de espaço da narrativa urbana, as narrativas que lidam com o regional passam a desenvolver uma tendência de agregarem a essa marca um elemento que se convencionou chamar "universalizante", profundamente ligado à condição humana. Essa "nova" mirada para o espaço regional extrapola fronteiras geopolíticas construídas, na direção da possibilidade de leitura por qualquer pessoa, de qualquer tempo e lugar, liberando-se de uma circunscrição regional a que estavam submetidos os textos produzidos até as primeiras décadas do século XX, muito em função da leitura feita pela própria crítica.

$O$ que alguns estudiosos denominam de ultrapassagem do regionalismo, no âmbito da literatura sul-rio-grandense, pode ser entendido como parte de um mesmo processo que, da Banda Oriental, Pablo Rocca chama "posgauchesca", ou seja, uma literatura, segundo ele, resultante do "efecto costumbrista más elemento humano" (2000, p. 11). Como o citado, outros críticos também se manifestaram a respeito da "ultrapassagem" promovida pela literatura regional, em relação aos limites de sua própria região, embora continue encontrando nela matéria literária, fincada no homem e no espaço com que ele interage durante sua 
Um corpus ficcional pampiano: o fronteiriço Sergio Faraco | 31 experiência de vida. É o caso, para citar alguns desses intelectuais, de Flavio Loureiro Chaves, Lígia Chiappini, Tania Carvalhal, José Clemente Pozenato, Léa Masina, Gilda Neves da Silva, lotados em torno da percepção de renovação da narrativa regional sulina.

Mesmo com o movimento de renovação da ficção regional que, no Rio Grande do Sul, Gilda Neves da Silva situa na esteira da obra de Cyro Martins e sua famosa "trilogia do gaúcho a pé", a pesquisadora encontra apenas dois escritores pertencentes à vertente regionalista no estado: Josué Guimarães e Sergio Faraco. Ambos tocados pela vertente social proposta pelo escritor de Quaraí, segundo a qual não há mais espaço para representar o gaúcho forte, altivo, heroico e que, nessa condição, movimenta-se em seu lugar de origem e de formação, o pampa, com liberdade, domínio e satisfação. Aos dois autores citados, acrescenta-se, no mesmo cenário, a obra do contista jaguarense Aldyr Garcia Schlee. Reforçamos, inseridas em um contexto de predomínio da narrativa urbana - e aqui se pensa nas cidades grandes e nos dramas, hábitos e preferências de quem nelas vive - e de desvalorização do texto de tradição rural, algo evidente na escrita da história e da crítica literária brasileira.

É nosso objetivo aqui, portanto, entender a obra de Sergio Faraco, considerando sua produção em um estado culturalmente reconhecido pelo culto da virilidade e força masculinas, cuja tradição se construiu sobre um tipo representativo essencialmente nutrido de tal caracterização e cuja origem remonta ao espaço do pampa sul-rio-grandense. Ambas na condição de integrantes nesse processo de revisão do mito e do tipo literário representativo do homem sul-rio-grandense dele derivado. Ambas na perspectiva de diálogo com a tradição legitimadora desse mito.

O contista em questão resgata o elemento espacial e humano regional, dirigindo um olhar lírico para o homem pequeno, sem dotes físicos e/ou posses materiais, mas ainda apegado ao seu chão e aos costumes e valores que dele conserva, os quais funcionam também como contraponto e resistência à massificação e à impessoalidade, caracterizadoras do espaço-tempo urbano. E pela ótica do homem comum, nascido na fronteira e, assim, acostumado a diariamente transitar por sobre as linhas divisórias, dialogam com a tradição a que nos referimos, bastante comprometida em construir a ideia dessa fronteira calcada na acepção de fechamento e de limite. No contexto em estudo, significa negar ou diminuir sobremaneira a comunicação cultural com os países platinos. A opção pela localização das narrativas no lugar pequeno e fronteiriço, portanto, encaminha seus textos a uma conversa com a tradição, em que ora se aproximam, ora se afastam das bases da mesma, 
32 | Fabiane de Oliveira Resende

na perspectiva de atualização dessa tradição de quase dois séculos que envolve o pampa.

No viés da representação do homem comum, pensada em simultaneidade com a perspectiva de fronteira aberta, no âmbito do sistema literário sul-rio-grandense, devem ser lembrados ainda os nomes de Luiz Sergio Metz e Cícero Galeno Lopes, contistas contemporâneos e que, em função do estabelecimento de um recorte, não integraram o corpus deste trabalho, que seria enriquecido, no entanto, com tal inclusão.

A tematização da fronteira e a recorrente localização espacial das personagens sobre a mesma, bem como a insistência em situações envolvendo o intercâmbio entre os países pampianos serão de extrema significação no entendimento da contística de Faraco e de Schlee. Representam, com os outros dois autores recém-citados, uma face da literatura sul-rio-grandense voltada ao espaço regional, compreendendo-o, por diversas vias, integrado ao universo do Prata. Assim, pelo viés da cultura, as fronteiras geopolíticas erguidas durante séculos são repensadas e deslocadas, como queria Angel Rama.

A intensa comunicação, que entendemos rotineira na visão dos dois autores, extrapola a produção ficcional de ambos, uma vez que se mostram também produtivos tradutores da literatura platina, trabalho fundamental para a divulgação da mesma do lado brasileiro. Essa relação de troca entre a literatura campeira produzida dos dois lados da fronteira, na esteira das palavras de Aldyr Schlee, é essencial para o conhecimento do regionalismo sulino.

\section{Sergio Faraco}

$\mathrm{Na}$ sua lida diária, de tropeadas secretas que varavam alambrados, de furtivas travessias do grande rio que corria em cima da fronteira, na sua lida de partilhas, miséria, punhaladas e panos ensanguentados, via a morte e a corrupção do corpo como outro mal qualquer, como os estancieiros, a polícia, fuzileiros e fiscais de mato [...]. 
(Do narrador de "Guapear com frangos", sobre a rotina de dificuldades de um tropeiro naquele lugar)

Sergio Faraco ${ }^{7}$ é autor premiado dentro e fora do Brasil, assim como ocorre com sua obra, traduzida para vários idiomas. As paisagens e os cenários de seu universo ficcional transitam entre o ambiente campeiro e o urbano, reunidos no volume Contos Completos, organizado pelo próprio autor e do qual trabalhamos com a "Primeira Parte", composta por catorze narrativas de temário regional, conforme o alargamento já destacado, proposto pelo Prof. Luis Augusto Fischer, segundo o qual, o texto regionalista deve ser pensado, nos dias de hoje, também como aquele ambientado na pequena cidade e seus arredores. Isso porque continuam a ser vistos como locais de resistência à massificação e à impessoalidade, vigentes nos grandes centros.

É o caso de Sergio Faraco que, a exemplo dos outros contistas citados anteriormente, elege a pequena localidade como cenário da parte de sua escrita que aqui nos interessa pensar. Nessa perspectiva do lugar pequeno, também irá se voltar à sua terra de nascimento, compreendida em conjunto com os arredores brasileiros e platinos, para compor seu universo ficcional e dai extrair os tipos característicos que o representam. Assim, as personagens das narrativas analisadas, em termos espaciais, estão localizadas no trânsito entre as cidades de Itaqui, Alegrete, Uruguaiana, Santana, Barra do Quaraí, São Borja, Maçambará, Alvear, Santo Tomé, Bella Unión, Monte Caseros, Curuzu Cutiá, percorrendo, no território sulino, uma região tão tradicionalmente cara ao regionalismo sul-rio-grandense quanto refratária à perspectiva de abertura em direção aos outros países pampianos, que as narrativas do autor alegretense sugerem de modo reiterado. Nesse trânsito espacial empreendido por personagens que transitam também entre as narrativas, destaque para os rios que o possibilitam, reforçando a referencialidade espacial pretendida, numa perspectiva realista de representação.

Os rios da região, em especial o Uruguai, assumirão grande significação na obra de Faraco não somente pelo reforço da referencialidade espacial, mas pela sugestão de travessia que carrega nos

\footnotetext{
7 Autor de Contos Completos, volume utilizado para a leitura neste trabalho, onde se estabeleceu a sigla CCm para as referências à obra em questão, de onde foram retirados os fragmentos citados.
} 


\section{4 | Fabiane de Oliveira Resende}

contos em estudo; por sua vez, bastante próxima à acepção de fronteira que, se não vem de forma explícita nos textos, é, no mínimo, latente. Eles proporcionam ainda o contrabando, intensa atividade econômica, lembrando Blau Nunes, praticada desde sempre no Rio Grande e representada com igual vigor na literatura de temário rural do contista em questão. Sendo assim, conforme observado por estudiosos, entre os quais, Léa Masina, a representação do contrabando é tema recorrente na literatura de fronteira, algo que se observa também do outro lado da mesma, na contística uruguaia e argentina.

O conto "Travessia” é emblemático em ambos os pontos: tanto no trabalho com a temática do contrabando quanto na sugestão trazida pela simbologia do rio. Nele, é flagrada a travessia de Joca, o tio velho, e seu sobrinho, ainda um menino, a bordo de uma chalana carregada de produtos contrabandeados, que garantiriam o sustento de ambos, do final de ano até o início do seguinte. Porém, com a chegada do barco da fiscalização, Tio Joca é obrigado a jogar toda a carga no fundo do rio. A travessia empreendida diz respeito não só ao deslocamento físico BrasilArgentina-Brasil, como também ao ritual de passagem do narradormenino para o mundo adulto, no caso, o da violência e do contrabando.

Em várias outras narrativas, o contrabando e os contrabandistas, "chibeiros" como os chamam os narradores, se farão presentes, via de regra, enfatizando que a atividade não é mais feita como antigamente: "a la farta” - tópico que serve ainda ao reforço da contraposição entre o tempo passado e o presente, algo recorrente nos autores aqui selecionados. Ao contrário, destacam que o contrabando vem diminuindo, uma vez que, de forma inversamente proporcional, aumenta a fiscalização por parte das autoridades. Nesse sentido, assim se expressa o narrador de "Bugio Amarelo", referindo-se à compra de munição do outro lado da fronteira para acabar com as caturritas que batiam na plantação, segundo ele, "Tipo de coisa que ninguém mais queria fazer, com medo da lei. Os tempos eram duros, os grandes lances iam rareando e a gente precisava se contentar com migalhas" (CCm, p. 65).

Os estancieiros e seus alambrados, estabelecidos à força da coesão e da bala das "vinchester", constituem símbolo da tomada da terra, também significativo no contexto de miséria em que vive o homem pequeno, sem posses e perspectivas. Os campos, então, vão "mermando", o que faz cair por terra o mito da democracia campesina, vigente durante muito tempo na literatura regionalista sul-rio-grandense. Nessa esteira, os chibeiros acabam ficando com seu raio espacial de atuação bastante 
restrito, gerando a revolta contra aqueles que entravam sua realização, tornados inimigos a serem combatidos.

O chibo representa, portanto, um importante meio de sobrevivência para o homem daquele lugar, considerando o comum, pequeno, despossuido, cada vez mais alijado. $\mathrm{Na}$ esfera dele se concentrarão os narradores de Sergio Faraco, inserindo sua literatura num processo maior, a que nos referimos anteriormente, de desmistificação do herói gaúcho e sua condição de representante paradigmático do povo sul-rio-grandense. Na esteira de Cyro Martins e Dyonélio Machado e no sentido de "perseguir" esse homem comum, visto em suas falhas e medos, aparecerão nos contos, o peão e o capataz de estância, o velho proprietário de um rancho quase em ruínas, o dono da pensão, a dona do prostíbulo, além dos pequenos contrabandistas, especialmente os de farinha, em suas rotinas não menos prosaicas, sem maiores arroubos e/ou complexidades psicológicas.

Por outro lado, costumam ser flagrados em seu lado mais instintivo, que os liga àquele meio natural de onde provêm ou que os circunda. Nesse sentido, a sensualidade feminina floresce num espaço ainda legitimado pelo masculino: da caça e do contrabando, das mortes violentas e da posse animalizada do corpo da mulher, o qual existe e é descrito na medida da satisfação das necessidades do homem. A mulher é carne que sacia o instinto do macho, para o que não carece de intelecto, cuja desvalorização é explícita no dizer de Cocona, a dona da casa de prostituição do conto "O voo da garça-pequena", a respeito da personagem Maria Rita: "Metida a ideias, mas no fundo boa pessoa" (CCm, p. 57).

A propósito dessa primazia do instinto, vejamos o relato do narrador de "Bugio Amarelo", do momento em que trai Amâncio - e por consequência o código de conduta que vem se mantendo, no universo rural, desde a formação do mito do gaúcho -, deixando-se levar pelo instinto de possuir a esposa do amigo, Zélia: "Enlouquecido, sem demora a derrubei no chão, esgarcei-lhe a calça e a galopei com tal sofreguidão que o gozo se me afigurou como um chupão na vida, quase desfaleço em suas pernas" (CCm, p. 67). No mesmo contexto, o desejo e a iniciação sexual de determinadas personagens reforçam a atuação dessa força instintiva, associada ao meio, a impulsionar o pacato viver das mesmas.

Os narradores, preferencialmente, posicionam-se fora do universo ficcional, caracterizando-se, segundo a classificação proposta por Gènette, como heterodiegéticos. Em tal condição, muitas vezes lançam mão da onisciência, informando ao leitor até mesmo a intimidade das 
personagens, como ocorre em "Dois guaxos", em que o narrador assume a visão de Maninho e dele revela sentimentos profundos:

Agora se acolherara com aquele traste indiático, aquele bugre calavera e muito alcaide, que viera do Bororé para ajudar na lida e era dia e noite mamando num gargalo e ensebando o baralho espanhol.

Da mana, ai, da mana não sentia raiva alguma, só uma dor no peito, só um caroço na garganta (CCm, p. 22).

A despeito desse mergulho ao íntimo das personagens, os narradores heterodiegéticos guardam uma distância do universo narrado, marcadamente temporal, estampada no uso dos verbos no pretérito imperfeito, que serve às descrições espaciais, e no pretérito perfeito, usado para o relato de um evento, ou na escolha do título "Lá no campo" [Grifo meu], ou ainda na narrativa "Guapear com frangos", em que se dirigem às personagens como "aquele López e mais certo Honorato...” (CCm, p. 44). $\mathrm{O}$ uso do demonstrativo que acabamos de grifar e de suas variações de gênero e número colabora para o efeito de distanciamento entre o narrador e o espaço narrado. Nos casos citados, a diferença entre o tempo da história e o da escrita aponta para narradores distantes do espaçotempo da primeira, o qual reconhecem como bastante diverso, se comparado ao presente, eminentemente no tocante à constituição e à aplicação da lei, bem como à presença das autoridades.

Os narradores homodiegéticos, na contramão, revelam envolvimento com o universo narrado: seja por participarem ativamente da dinâmica sócio-econômica do mesmo, em parceria com comparsas, nas atividades de caça de animais e de contrabando e nas mortes violentas que executam ou presenciam, consideradas sempre as dificuldades materiais e físicas que o espaço impõe; seja por comungarem um código de conduta próprio do universo em questão, herdeiro do praticado pelo gaúcho-mito. Exceção feita ao narrador do conto "Sesmarias do urutau mugidor", também participante do universo narrado, porém, sem pertencer a ele. Isso por se tratar de um escritor vindo da cidade, o qual chega a um rancho nos arredores de Uruguaiana e Alegrete, onde é recebido pelo velho proprietário. Este o acaba vendo com desconfiança por ser ele um homem citadino, das letras, enfim, um forasteiro naquele lugar. Em todos os casos, os narradores homodiegéticos não se nomeiam, embora constituam personagens atuantes nas respectivas histórias. Via de regra, compartilhadas com quem chamam de "comparsas", isto é, os 
companheiros de aventuras vividas nas mortes por acerto de contas, nos roubos de animais, nos contrabandos e nas travessias frustradas, entre os quais Pacho, personagem que participa de várias narrativas envolvendo tais eventos, ordinários naquele universo.

Independentemente da distância ou da proximidade do universo narrado, os narradores expressam-se por meio de uma linguagem híbrida, tanto no que se refere ao uso corrente e diverso de espanholismos, quanto à utilização de termos regionais, típicos da coloquialidade, costurados à fala culta de narradores que, com Eoná Ribeiro, lembramos, também relatam para homens cultos da cidade. Num caso e noutro, não há qualquer marca tipográfica que os saliente ou os diferencie em relação ao restante do texto, seja nas falas do narrador e/ou nas das personagens. $\mathrm{O}$ que indica a naturalidade com que se encaixam na fluência sintática do discurso, para a composição de um idioma fronteiriço, formado pelo encontro entre duas línguas e pela mescla da linguagem regional com a norma culta padrão, conforme lemos em "A voz do coração", na fala do narrador, descrevendo a paisagem dos campos que percorriam: "Não muito longe, o alarido dos cachorros. Gordo e seus homens deviam andar pelas três restingas que recém cruzáramos. Coisa de dez minutos, se tanto, a cuscada vinha zebuar no garrão da gente" (CCm, p. 51).

A propósito do uso de espanholismos, o conto "Hombre" encerrase com o narrador concluindo o seguinte a respeito do companheiro Pacho: "Tinha uma voz horrivel, taurina, mas a milonga que mugia calava fundo em meu coração, falava de amigos mortos, homens que tenían algo más que leche en los cojones" (CCm, p. 88). Outro exemplo dessa natural incorporação do idioma espanhol pode ser visto na narrativa "Guapear com frangos": "E ele voltava a pensar, a perguntar-se, logo ele, que não tinha o costumbre malo de se quedar cismando, imaginando coisas, como os doutores, os preguiçosos e os jacarés" (CCm, p. 47).

Nas vezes em que cedem voz às personagens, permitem novamente a expressão do encontro dos idiomas, a exemplo do que lemos no diálogo entre López, um contrabandista, e Cocona, a proprietária do "La Garza”, quando ela lhe esclarece acerca da encomenda de um rádio a ser comprado do outro lado da fronteira: “- Un rojo como el de la Paragua e como López resmungasse, cortou: - Ni un peso más” (CCm, p. 58). Na mesma narrativa, o narrador incorpora à sua a fala castelhana da personagem recém-citada: "Sí, verdad, Cocona sentou-se e fez um gracejo malicioso por causa dos odores que ele dizia sentir" (CCm, p. 57). Assim praticada, a linguagem torna-se um meio de aproximação com o universo da fronteira e de representação do mesmo. 
38 | Fabiane de Oliveira Resende

O universo da tríplice fronteira também está presente no discurso dos narradores, na invocação plástica do ambiente campeiro que promovem, sem chegar a constituir as chamadas "manchas descritivas", mas salientando a toponímia, os elementos físicos da paisagem e outros construídos pelo homem; somados, constituem uma região de intenso trânsito de pessoas, mercadorias, costumes e falas.

Marcadamente campeira, a região assim se afirma também em razão do contraponto que estabelece com a realidade e os hábitos e valores citadinos, conforme vimos observando, um tópico bastante visado pelos narradores estudados na presente pesquisa. Em "Sesmarias do urutau mugidor", segundo já citamos, o homem urbano, letrado, é visto com desconfiança pelo velho proprietário do rancho. Diz o escritornarrador, incorporando à dele a fala do rancheiro: "Perguntou se eu vinha de longe. Ah, Porto Alegre? E espichou o beiço mole. Teria preferido, talvez, que eu viesse de Alegrete ou de Uruguaiana, de Santana ou Quaraí, forasteiro mais a jeito de lindeiro [...]" (CCm, p. 72). No conto "Velhos", o contraste entre os dois ambientes fica claro na chegada do noivo de Maria Luiza à estância dos pais da moça, que coincide com a do irmão do capataz e sua mulher; aquele vem de carro e estes, a cavalo. $\mathrm{O}$ narrador assim relata: "Já o tal noivo, como Sizenando, vinha aos domingos, mais ou menos à mesma hora, e duas ou três vezes o obrigara a pular fora da estrada, além de sufocá-lo na poeira" (CCm, p. 89). Maria Luiza, por sua vez, "que sempre depreciara a mesmice do campo, de súbito passara a preferi-la, nos fins de semana, à variedade citadina" (CCm, p. 89).

Em "Hombre", o antagonismo entre o ambiente urbano e o rural é textualizado pela personagem Pacho, companheiro do narrador num roubo e caça de animais que garantiria maior abastança ao batizado do dia seguinte. Diante da inabilidade mostrada pelo comparsa, Pacho desabafa:

- Trocou o rio pela cidade, pela capital, virou homem de delicadezas, empregado de patrão, trocando a amizade dos amigos pelo esculacho dos endinheirados. Pra que serve tudo isso? Agora taí, um pobre-diabo que não presta mais pra nada. Dispara feio num capincho e no primeiro entrevero se borra nas calças (CCm, p. 87).

$\mathrm{Na}$ fala da personagem, fica clara a distinção em vários âmbitos a separar os dois espaços e a consequência no ser daquele homem que, após 
ter se mudado para outro espaço, não consegue, uma vez de volta, reconhecer-se no primeiro, de origem. A ausência de reconhecimento, mais uma vez, é fruto do deslocamento espacial, propiciador de outras vivências e experiências modificadoras do indivíduo. Sendo assim, este, ao voltar, percebe-se não mais o mesmo, visão baseada no decréscimo visível de sua performance como atirador, na tentativa frustrada da caçada com Pacho. Ele próprio promove tal constatação: “Apontei no entreolho, constatando, aborrecido, que meu braço tremia - ô saudade daquele velho tempo, Pacho no remo e comigo a vinchester mortal, rescendendo a graxa e querosene..." (CCm, p. 83).

Com o exemplo anterior, estamos novamente diante de um motivo que vem se mostrando recorrente na contística analisada: o retorno ao espaço de origem como necessidade que os homens ligados à tradição campeira demonstram, mesmo tendo migrado para um lugar de vivência bastante diversa. Além da narrativa citada, o conto "Dois guaxos" também serve para ilustrar o que estamos afirmando: a personagem Maninho resolve ir embora, por já não suportar mais ver Ana, sua irmã, a se assanhar com um índio bugre. Deseja ganhar o mundo e conhecer outros lugares e gentes. No entanto, sem sequer ter ido, já pensa no retorno: "[...] talvez até voltasse. [...] Voltar para subir o cerrito de pedra nos fundos do campinho, para atirar uma flor na cruz da velha morta, de quem, agora mais do que nunca, sentia tanta saudade" (CCm, p. 25). Assim que a falta sentida em relação ao lugar de origem, referência maior do homem, também é tocada pela contística de Sergio Faraco que, nesse momento, reforça a tradição pampiana, remontando aos primeiros textos da gauchesca platina e sul-rio-grandense, empenhados em representar o gaucho/gaúcho, antes de tudo, como ser essencialmente telúrico.

É importante destacar, contudo, que, tomando a obra ora analisada e os homens e mulheres nela representados/das, a expressão do telurismo não é forte o suficiente para constituir uma marca da escrita de Faraco, no sentido de uma expressão explícita de apego ou de amor ao chão. Observamos, isso sim, a representação de homens, mulheres e crianças em sua rotina de dificuldades intimamente relacionadas ao meio onde vivem e as condições forjadas para superá-las: personagens que, dia a dia, necessitam lutar contra os obstáculos físicos, impostos por esse mesmo meio, o qual não oferece outras possibilidades que não a de enfrentá-los. O conto "Guapear com frangos" constitui claro exemplo dessa luta, que recai na tarefa delegada a López, de levar o tropeiro morto Guido Sarasua, em acordo com a "obrigação de não deixar corpo de homem sem velório" (CCm, p. 44). Durante o trajeto, vários são os 
40 | Fabiane de Oliveira Resende

obstáculos: desde a chuva intensa até o ataque dos urubus, que acabam por devorar o corpo quase por inteiro. No relato de uma caçada realizada nas terras de um estancieiro desonesto e cruel, o narrador de "A voz do coração" assim descreve o espaço onde a realizam:

Tiro de meia légua? Dava mais, e se era campo aberto também era pedregoso, mosqueado de cupim e tacuru e cova de touro, impossível bandeá-lo às carreiras sem trompar de pé e encalacrar o peito de seixinho miúdo e estrumeira. Mas ninguém nos viu e ao rio chegamos ressolhados, quase sem poder falar. Vadeamos com água ao peito, acima da cabeça a munição e a armaria (CCm, p. 53).

Além das dificuldades relativas ao meio físico, enfrentadas pelas personagens no empreendimento de suas atividades rotineiras, há ainda aquelas criadas pelo homem e suas leis injustas, que favorecem os poderosos. Agregados a tais leis, vêm ainda o abuso de autoridade, a desigualdade na distribuição das posses e riquezas, a escassez no meio de trabalho, o estabelecimento de alambrados, a desconstituição de famílias e as necessidades por que passam muitas delas. Logo, configura-se uma situação de carência das mais variadas ordens, a que o foco dos narradores de Faraco mostra-se comumente sensivel e atento. Assim, em inúmeros contos, descrevem o espaço narrado como o "cu do mundo", onde "o que podia fazer um desgraçado senão ouvir a voz do coração?” (CCm, p. 55). Em outra narrativa, "Manilha de espadas", semelhante visão relativa ao espaço é externada, à medida da sua escassez até mesmo em termos de opções de entretenimento:

Que outro passatempo encontrariam os homens naquele rincão olvidado pelo mundo? Uma rua principal, descalçada, cortada por outras que eram quase trilhas, uma barbearia, um bolicho, uma ferraria, o remédio era carpetear com Pepeu Gonzaga, pois a Boate Copacabana, lá na ribanceira do arroio, o comissário tivera de fechar porque a proprietária se arrenegava de pagar por mês a proteção (CCm, p. 29).

$\mathrm{Na}$ citação anterior, a representação da falta de opção aparece relacionada à forma abusiva como a lei é imposta e exercida, situação 
Um corpus ficcional pampiano: o fronteiriço Sergio Faraco | 41

clara no recém-citado "A voz do coração": "Orlando Faria, o Gordo era estancieiro de conceito no distrito, meio prefeito, meio delegado e meio uma porção de coisas que ele mesmo se nomeava e ninguém dizia que não" (CCm, p. 52). A indignação diante desse abuso contra os "pequenos" recai também na figura dos fuzileiros, cobradores de impostos, policiais, guardas aduaneiros e fiscais de mato.

Esse espaço à margem da lei, onde manda quem pode, é também caracterizado pela distância e pelo silêncio circundantes, aspectos significativos na constituição das personagens e logo notados pelo escritor porto-alegrense recém-chegado à região. Assim registra a cena vista, com o velho inserido no contexto da paisagem que o rodeia: "Que pena, eu pensava, um pobre velho sozinho naquelas lonjuras, [...]” (CCm, p. 75). A distância mencionada carrega consigo a percepção do esquecimento a que é relegado o lugar, desprovido da ação igualitária da lei e de oportunidades de ascensão social e econômica.

Em consequência, paralelo à "lei dos estancieiros", vige um código de conduta moral próprio, herdeiro daquele construído ao tempo de formação do mito e que, transposto para a atualidade do contexto em questão, naturaliza as mortes, tanto por acerto de contas quanto para lavagem da honra e justifica a prática do contrabando e do roubo como necessária em um universo de tanta precisão e escassa oferta. Basta atentarmos, na direção tomada, para o título "Noite de matar um homem", conto em que o narrador e seu companheiro Pacho vão à caça de outro chibeiro, a que chamam o Mouro, plenamente respaldados pelas leis do código que acabamos de citar. Nas palavras desse narradorpersonagem,

[...] Mouro fizera daquela costa seu rincão. Dado ao chibo como nós, ninguém lhe desfeiteava o afazer, mas, com o tempo, campos e matos da fronteira, por assim dizer, foram mermando, e já não era fácil repartir trabalho. Seguido Tio Joca dava com ele no meio do negócio, e se o ganho era escasso ficava ainda menor. Ele também se prejudicava e por isso se tornou mais façanhudo, mais violento, tão atrevido que em Itaqui apareceu o nome dele no jornal. Era o que faltava para atiçar a lei. [...] Tio Joca armou um cu-de-boi e todos estiveram de acordo em que o remédio era um só (CCm, p. 39). 
42 | Fabiane de Oliveira Resende

$\mathrm{O}$ anúncio feito pelo título e o fragmento transcrito encaminham a leitura da morte do Mouro, justificada na "ética" que deve reger o "ofício" e na necessidade de sobrevivência diante de uma situação sócioeconômica a qual não fora criada por aqueles homens que agora precisavam fazer justiça com as próprias mãos. Legitimado no mesmo jargão, o narrador de "Bugio Amarelo" mata o alemão dono da pulperia, depois de saber do envolvimento deste com Zélia, por sua vez, mulher de um grande amigo. Em nome da amizade entre eles e da traição empreendida, só resta executar a morte em defesa da honra do homem traído. O que é contado e transmitido como grande façanha entre os chalaneiros da região, acrescido dos floreios de Bagre, também testemunha do adultério de Zélia. No conto "Hombre", para finalizar o elenco de exemplos relativos ao ponto em discussão, Pacho faz furos na embarcação dos capangas de um estancieiro, que vigiavam os campos onde pretendia caçar com seu companheiro, o narrador do texto, enquanto aqueles "farreavam" com o "chinaredo". Quando a embarcação começa a afundar, Pacho vê com naturalidade o fato de já haver ocupantes da mesma no fundo do rio, consequência previsivel diante da atitude que se vira obrigado a tomar. Ao que responde seu companheiro: "- Grande!"

Os exemplos arrolados são suficientes para atestar a violência como integrante da rotina de vida das personagens, por acreditarem que ela é o único caminho para a solução dos problemas impostos pelo meio, donde vem sua legitimação; e como determinante para a conduta e o comportamento dessas personagens. A noção de naturalização da violência é passada de geração em geração e até mesmo as crianças já aprendem a ter contato com ela, como sendo algo inerente àquele espaço. Nessa esteira, faz sentido o fato de em metade das narrativas haver mortes, em sua maioria, por conta de assassinatos.

A região da fronteira, compreendida em suas pequenas cidades, povoados e campos ao redor constitui-se, portanto, longínqua e violenta, aspectos que a caracterizam de forma contundente ao longo do conjunto de narrativas analisadas. Por tal ângulo é percebida pelos narradores, em termos de representação desse espaço e dos seus habitantes. Uma "fronteira triste", segundo o dizer do narrador de "Guapear com frangos", a abrigar "tropeiros, chibeiros, pescadores e ladrões de gado" (CCm, p. 47), todos ofícios desenvolvidos na medida da relação com o espaço em foco, que se apresenta móvel e marginal. A respeito disso, assim reflete Pacho, personagem do conto "Hombre", num diálogo que mantém com o companheiro de caçada, acerca do modo como são levadas as coisas 
naquele lugar: "- Imundo? Ora, a gente fica que nem porco, se acostuma com tudo" (CCm, p. 87).

A marginalidade geográfica determinada pela distância dos grandes centros - realidade comum aos dois lados da fronteira - acaba por contribuir para a situação de marginalidade sócio-econômica, detectada pelos relatos. A região da fronteira ${ }^{8}$, sob a lente dos narradores de Faraco, apresenta-se carente de oportunidades de toda a ordem, considerando o ângulo de visão comum, adotado por eles na totalidade dos contos: o do pequeno, traduzido em várias representações, o peão, o chibeiro, a mulher, o capataz, o tropeiro. Por aí percebem e retratam a "realidade" do lugar, ao longo de relatos que francamente irão privilegiar tal ponto de vista, em detrimento daquele tido como hegemônico na região: o dos estancieiros, tanto rio-pratenses quanto sul-rio-grandenses. Ambos são considerados inimigos na mesma medida, reforçando a noção de uma fronteira aberta, com os dois lados vivendo semelhante situação: a luta pela sobrevivência contra os poderosos e usurpadores. Estes, em especial os estancieiros, não costumam ter voz nas narrativas, sendo apenas citados pelos nomes e pela condição de inimigos dos homens comuns recém-citados. $\mathrm{O}$ mesmo raciocínio pode ser aplicado no tocante às autoridades policiais: a instituição e quem a constitui representam o inimigo, o qual, assim visto, independe de nacionalidade, sustentando a ideia de que os abusos são cometidos lá e cá e sempre na direção do homem comum, fragilizado e vulnerável.

$\mathrm{O}$ povo, modo como alguns narradores chamam o lugar onde são ambientados os relatos, além de ser o mesmo utilizado pelos narradores de dois contistas uruguaios trabalhados em outro momento, também guarda inúmeras semelhanças com os pueblos descritos nos contos de Eliseo Porta e Juan Capagorry, o que reaviva o contato entre as duas margens do rio Uruguai. Dentre elas, a mesma condição de arredores formados por campos e silêncio; os ranchos pobres; o trânsito dos chibeiros; os bolichos e as conversas em seu interior; a alusão aos recuerdos

\footnotetext{
${ }^{8}$ É importante destacar que os contos de Faraco, conforme anteriormente afirmamos, citam várias vezes nomes das cidades dos dois lados da fronteira, permitindo a ancoragem referencial do universo literário explorado e uma situação precisa, por parte do leitor, do local ficcionalizado. No entanto, suas narrativas nunca passam exatamente nas referidas cidades, senão em locais imprecisos: uma estância ou um rancho nas lonjuras, próxima/o a um povo, no cruzamento de um rio ou de um campo agreste, visão que, de algum modo, é semelhante à dos autores uruguaios aqui estudados, no sentido de conceber o espaço pelo viés da generalidade, do comum a uma coletividade, desconsiderando, muitas vezes, inclusive, fronteiras geopoliticas.
} 


\section{4 | Fabiane de Oliveira Resende}

que eles suscitam e que os formam; os mesmos eventos capazes de concentrar em torno de si toda a comunidade, caso dos velórios e dos enterros; a superstição e o acervo lendário como fonte de conhecimento que também contribui para o saber e a formação cultural das coletividades envolvidas, baseados no empirismo e na sobrenaturalidade, e também no pacto de crédito que é dado a ela e as suas manifestações no interior dessas mesmas coletividades.

O contrabando intenso, cuja exploração literária tem semelhante intensidade na literatura de Faraco, serve também à expressão clara da comunicação entre os dois lados da fronteira e da visão de abertura que motiva o olhar para a mesma. Isso pelo fato de ser igualmente claro que esse ir e vir diuturno, constante não somente transporta mercadorias, senão também promove intensas trocas culturais, materializadas na expressão linguística, no jeito de vestir, nas armas utilizadas pelos campesinos para o cumprimento de seus ofícios, na música, pontualmente na milonga e no chamamé, na culinária, nos hábitos de lazer, dentre outras. Nos contos "Travessia” e "O voo da garça-pequena”, para ficar com apenas dois exemplos, é nítida a intenção do narrador, de comprovar, na prática do próprio discurso, ao incorporar à sua, a fala castelhana, respectivamente das personagens Dona Zaira e Cocona, o movimento natural de interpenetração dos dois idiomas em questão. $\mathrm{O}$ resultado é uma produção híbrida, a qual também aponta para a noção de fronteira compreendida no sentido de sua porosidade.

A fronteira pampiana comparece aos textos em sua acepção física, visualizada nos rios e campos agrestes a serem atravessados e "domados" dia e noite. Sendo assim, fronteira, aqui, é essencialmente trânsito, movimento que borra as linhas divisórias, criadas, neste caso, entre o estado sul-brasileiro e os países rio-pratenses e sustentadas por uma tradição que, do lado de cá, manteve viva a ideia do castelhano como outro, diferente, em primeira e última instâncias, como inimigo a ser combatido. Algo revisto nos contos analisados, que tendem a incorporar com naturalidade a noção de mescla e de interatividade - nos âmbitos já mencionados e em outros - em substituição à visão de segregação que caracterizou durante muito tempo a literatura regionalista sul-riograndense, no que se refere ao contato com o universo platino.

Da dupla possibilidade de pensarmos a fronteira, citada pela historiadora Sandra Pesavento e transcrita no primeiro capitulo deste estudo, nas narrativas em questão, o olhar dirige-se para a faceta de abertura. Não somente nas acepções físicas e simbólicas destacadas, como também no que se refere à composição dos textos. $\mathrm{O}$ que reside no fato 
de a totalidade das narrativas não ter um encerramento efetivo, ficando em aberto. Essa opção também as insere em seu tempo de produção, cuja tendência é a da maior participação do leitor na construção e no preenchimento de lacunas do texto. Dessa forma, são encerradas em pleno desenvolvimento de uma ação; em diálogos que não terminam, pela falta ou imprecisão de uma resposta; ou nas incertezas e lacunas deixadas pelo narrador.

Fronteira, por tudo o que foi dito, é espaço percebido e tematizado nas travessias dos chibeiros e nas promovidas entre o mundo infantil e o adulto e no meio de um caminho que encerra o conto. Suas possibilidades de mirada e significação são percebidas e interpretadas em vários momentos e instâncias dos textos; como ocorre, por exemplo, nos casos do narrador de "Travessia", que se inicia no contrabando, e no da personagem "guri", de "Aventura na sombra", cujo ritual de passagem se dá no âmbito sexual. Em "Noite de matar um homem", o narrador, que parece ser o mesmo de "Travessia", em função do comportamento que apresenta, revela-se um novato também na prática de matar, iniciando-se, portanto, no mundo do crime. Após a primeira morte, cometida "no susto", conta ele: "Recuei, não podia desviar os olhos e fui-me afastando e me urinava e me sentia sujo e envelhecido e ainda pude ver, horrorizado, que aquela mão agora estava aberta e empalmava só a gaitinha" $(\mathrm{CCm}, \mathrm{p}$. 42). A intensidade extrema trazida por experiências semelhantes à citada justifica a sensação de salto temporal aludida pelo narrador. E com ela, novamente, está presente a simbologia da travessia, ocorrida entre o mundo infantil e o adulto.

Como podemos ver, os textos de Faraco são bastante impregnados da noção de fronteira aberta e das múltiplas possibilidades de significado que a mesma encaminha. Ao contrário dos contistas uruguaios, mais voltados ao interior do país, o universo ficcional do autor alegretense volta-se para "fora", no sentido da consideração do mundo platino e seus influxos. Numa aderência explícita ao ponto de vista do homem comum, os contos desenham a região eleita cenário de ficção em suas carências, sem abrir mão de certa poeticidade, sugerida no movimento cíclico de amanheceres e anoiteceres, flagrados no espaço de vastidão da planície pampiana. 
46 | Fabiane de Oliveira Resende

\section{REFERENNCIAS}

ARREGUI, Mario; FARACO, Sergio. Diálogos sem fronteira. Trad. e notas de Sergio Faraco. Porto Alegre: LP\&M, 2009.

BERND, Zilá. (org.) Dicionário de figuras e mitos literários das Américas. Porto Alegre: Ed. da UFRGS/Tomo Editorial, 2007.

BITTENCOURT, Gilda Neves da Silva. O conto sul-rio-grandense: tradição e modernidade. Porto Alegre: Ed. da Universidade Federal do Rio Grande do Sul, 1999.

Conto e identidade na América Latina. Organon. Porto Alegre, v.17, dez. 2003, p.23-28.

CANDIDO, Antonio. Formação da literatura brasileira: momentos decisivos. Belo Horizonte: Itatiaia, 2000.

CARVALHAL, Tania Franco. Fronteiras em literatura. In: Práticas de integração nas fronteiras: temas para o Mercosul. In: CASTELLO, Iara Regino et al. (orgs.) Porto Alegre: UFRGS/Instituto Goethe, 1995. p. 160-174.

- (coord.). Culturas, contextos e discursos: limiares críticos do comparatismo. Porto Alegre: Ed. da Universidade Federal do Rio Grande do Sul, 1999.

O próprio e o alheio. Ensaios de literatura comparada. São Leopoldo: Editora Unisinos, 2003.

CECCHIA, Cristiane. Identidade e violência na literatura argentina: uma leitura de "El camino de la costa", de Juan José Saer. Disponivel em: www.letras.ufmg.br Acesso em: 28 nov. 2011.

CHIAPPINI, Lígia; MARTINS, Maria. Helena; PESAVENTO, Sandra (org.). Pampa e cultura. Porto Alegre: Editora da UFRGS/IEL, 2004.

; MARTINS, Maria Helena (orgs.) Cone Sul: fluxos, representações e percepções. São Paulo: Hucitec, 2006. 
Um corpus ficcional pampiano: o fronteiriço Sergio Faraco | 47

FARACO, Sergio. Viva o Alegrete: histórias da fronteira. Porto Alegre, L\&PM, 2001.

. Contos Completos. Edição atualizada. Porto Alegre: LP\&M, 2004.

FISCHER, Luís Augusto. Conversa urgente sobre uma velharia - uns palpites sobre vigência do regionalismo. Cultura e pensamento. n. 3, dez. 2007, p. 127-139.

GUTFREIND, Ieda. A historiografia rio-grandense. Porto Alegre: Editora da Universidade/UFRGS, 1992.

KAHMANN, Andréa C. Fronteira, identidade, narrativa: tradição e tradução em Sergio Faraco. 126f. [Dissertação de Mestrado]. Programa de PósGraduação em Letras. Universidade Federal do Rio Grande do Sul, Porto Alegre, 2006.

LUDMER, Josefina. O gênero gauchesco: um tratado sobre a pátria. Trad. de Antônio Carlos Santos. Chapecó: Argos, 2002.

MARTINS, Maria Helena (org.) Fronteiras culturais: Brasil - Uruguai Argentina. São Paulo: Ateliê Editorial, 2002.

MASINA, Lea. A exclusão do diálogo com o Prata no discurso crítico brasileiro. In: PALERMO, Zulma (coord.) El discurso crítico en América Latina. Buenos Aires: Corregidor, 1999.

- Tradição, transformação e renovação na literatura sul-riograndense de fronteiras. Organon. Porto Alegre, v.17, p. 45-51, dez. 2003.

PESAVENTO, Sandra Jatahy (org.) Fronteiras do Milênio. Porto Alegre: Editora da Universidade Federal do Rio Grande do Sul, 2001.

PIZARRO, Ana (org.) América Latina: palavra, literatura e cultura. São Paulo: Memorial; Campinas: UNICAMP, 1994.

RAMA, Angel. Transculturación narrativa en America Latina. México: Siglo XXI Ed., 1982. 
RAMIL, Vitor. Estética do frio: conferência de Genebra. Porto Alegre: Satolep, 2004.

RESENDE, Fabiane O. Pampa. In: BERND, Zilá (org.) Dicionário de figuras e mitos literários das Américas. Porto Alegre: Ed. da UFRGS/Tomo Editorial, 2007. p. 499-505

. Contrabando no pampa: literatura de fronteira. In: Anais do II Congreso Internacional del Conocimiento. Santiago: Universidad de Santiago de Chile, 2010. Disponível em: <http://www.internacionaldelconocimiento.org/congreso2010〉.

ROCCA, Pablo. Uma literatura de fronteira: Jorge Luis Borges, ficções e debates. Disponível em:

<http://www.letras.ufmg.br/poslit/08_publicacoes_pgs/Eixo\%20e\%20a \%20Roda\%2018,\%20n2/07-Pablo-Rocca.pdf>. Acesso em: 25 ago. 2010.

SCHLEE, Aldyr Garcia. Devaneio testemunhal sobre literatura de fronteira e fronteiras literárias. In: Anais do III Seminário Internacional de História da Literatura. Porto Alegre: PUCRS, 2000.

SCHLICKERS, Sabine. Que yo también soy pueta": la literatura gauchesca rioplatense y brasileña (siglos XIX-XX). Madri: Iberoamericana/Vervuert, 2007.

Recebido em: 26/08/2016

Aceito em: 12/09/2016 